\title{
Spatial distribution of ultrafine particles at urban scale: the road-to-ambient stage
}

\author{
F. Costabile ${ }^{1}$, B. Zani $^{2}$ \& I. Allegrini ${ }^{1}$ \\ ${ }^{1}$ Institute for Atmospheric Pollution-National Research Council \\ (CNR-IIA), Monterotondo-Rome, Italy \\ ${ }^{2}$ ARPA Parma, Italy
}

\begin{abstract}
The spatial variability of ultrafine particles (UFPs) is believed to be an important issue to assess urban air pollution fate and exposure in connection with traffic motorised emissions. In this work, the high-time resolution total number concentration of UFPs was measured at traffic-oriented and urban background locations in a middle-size city in Italy. The major objective was to study valuable connections with local traffic sources, as well as measurement sites' representativeness. On the one hand, it was found that the total concentration at the traffic site can be representative of vehicle exhaust sources in ambient air. On the other hand, it was possible to identify three prevailing contributions for the total UFPs number concentration at urban scale: a very low urban background concentration, a significant contribution due to local traffic sources, and a significant contribution due to secondary transformation processes closely linked to meteorology.
\end{abstract}

Keywords: urban air pollution, ultrafine particles, traffic emissions, background, representativeness, exposure.

\section{Introduction}

During the last decades a growing body of research has investigated worldwide the extremely vast subject of urban air quality [1]. Measuring any potential effect of any urban air pollutant requires the understanding of its variation and distribution in both space and time. Traffic-related pollution and its spatial variations are particular concerns; a comprehensive understanding is crucial [2- 
8]. However, current actions are particularly hampered by a lack of knowledge when characterising the spatial variability within urban areas [9].

For particles, the spatial variability is particularly relevant, and depends on the size fraction. Particles smaller than $100 \mathrm{~nm}$ (the so-called ultrafine particles, UFPs) are more variable in space and time than fine particles as they have a higher dependence on particle sources, and a faster removal from the atmosphere [10-12]. Consequently, their spatial variability is believed to be an important issue to assess air pollution fate and exposure.

Internal combustion engines are known to be a major emission source of UFPs [13-17]. However, in spite of extensive laboratory studies on engine emissions, there are few investigations of how particle mobile emissions evolve and affect air quality establishing a link between sources and receptors [18-20]. It has been shown that the size distribution of emitted particles evolves substantially within a few hundred meters of emission $[8,21]$. After release into the atmosphere, UFPs are subjected to complex dilution and transformation processes. Neither current models nor those that will be available in the near future are tough to be able to cover all the spatial and temporal scales that are involved from the emission (centimetres, milliseconds) to the urban/regional scale (kilometres, hours) [22].

In this work, high-time resolution UFP total number concentration was measured in a middle-size urban area of Italy (Parma). The major objective was to study valuable connections with local traffic sources, as well as the measurement sites' representativeness [23].

\section{Experimental}

A Water-Condensation Particle Counter (WCPC,TSI Mod. 3781, Figure 1 and Figure 2) [24-27] was used to measure the concentration of particles in air with a diameter larger than $6 \mathrm{~nm}$ (and smaller than $3 \mu \mathrm{m}$ ), $\mathrm{N}_{6}$,
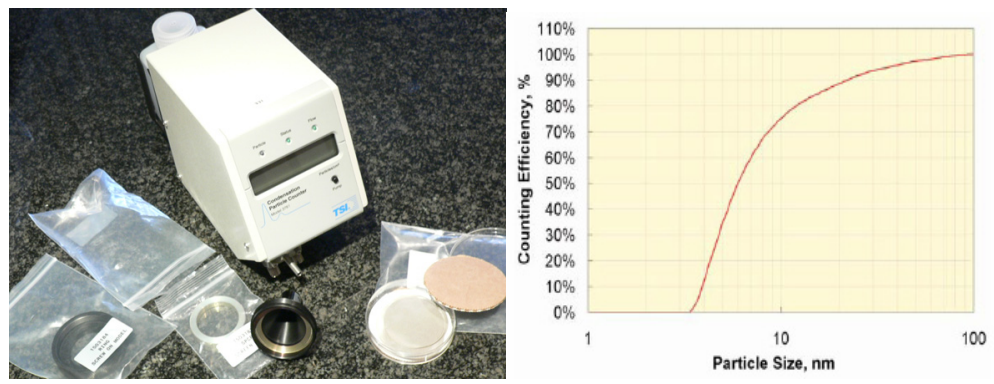

Figure 1: $\quad$ Picture and counting efficiency of the Water-Condensation Particle Counter (WCPC,TSI, Modello 3781) [28].

Data were collected every 2 seconds, and then averaged to generate 1-minute values. Measurements were taken during the winter (January, February and March) and summer (July, August, September) of 2007 (both weekdays and 
weekends). Instruments were located at two urban sites, 740 meters away from each other in Parma downtown: via Montebello, and Parco della Cittadella (Figure 3, Figure 4).

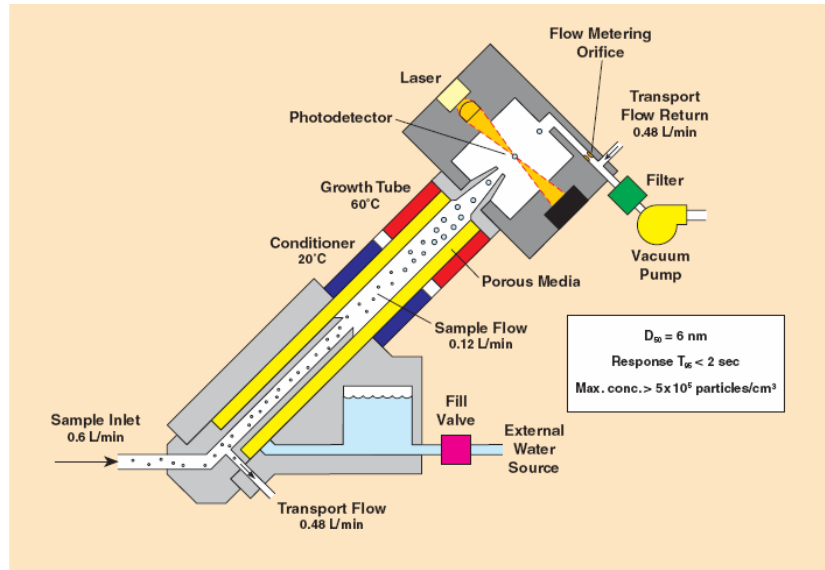

Figure 2: Working principle of the Water-Condensation Particle Counter (WCPC,TSI, Modello 3781) [28].

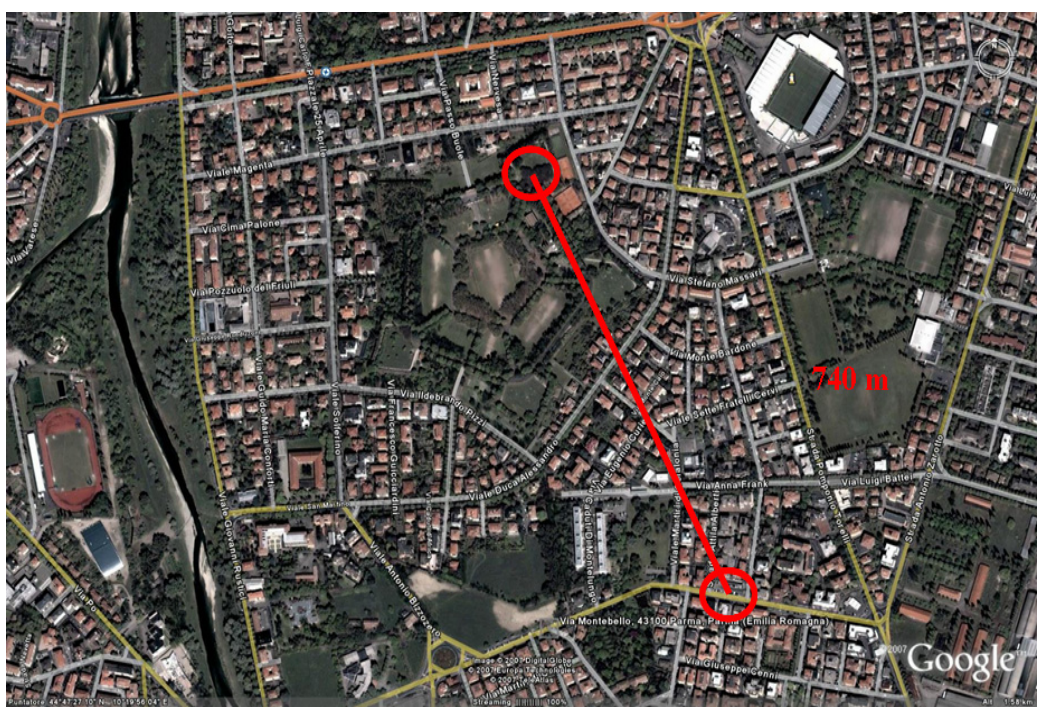

Figure 3: Picture by Google Earth of the two measurement sites in Parma: Parco della Cittadella (top) and via Montebello (bottom).

Representativeness criteria with respect to emission sources drove the selection of these two sites [29, 30]. Parco della Cittadella was selected as representative of urban background concentrations, the closest traffic emission 
source being around 100 meters away. Conversely, the traffic site in Via Montebello would reflect pollution concentrations strongly influenced by urban traffic emissions; measurements were taken less than 1 meter from the road (the road is south of the measurement point, Figure 4). The sampling probe was made by a straight stainless steel tube, with $7 \mathrm{~mm}$ internal diameter and length $<15 \mathrm{~cm}$, in order for the sampling losses to be negligible. A small cyclone was used at the traffic site (where the concentrations were expected to be higher) to avoid particles larger than $1 \mu \mathrm{m}$ to either block or damage the system.
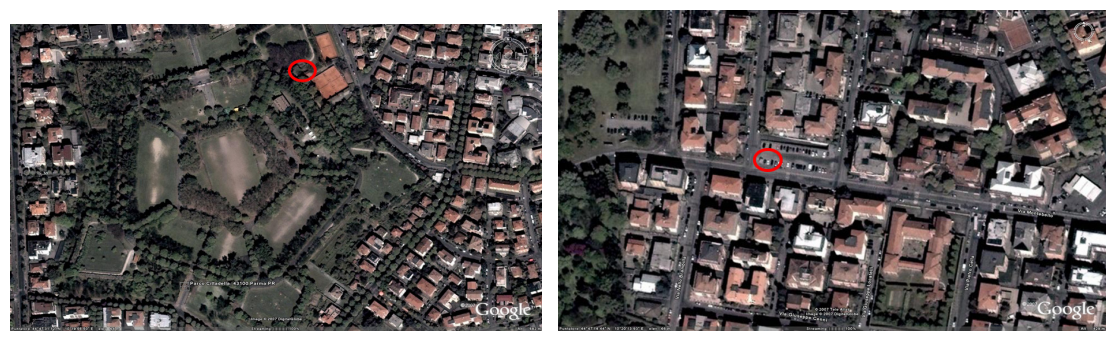

Figure 4: Details by Google Earth of the two measurement sites in Parma: Parco della Cittadella (left) and via Montebello (right).

\section{Results and discussion}

\subsection{From traffic site to urban background}

The total number concentrations of UFPs measured (Figures 5-8) were found to be low, but comparable to similar works [31]: urban background locations have usually average concentrations of $10.000 \mathrm{\#} / \mathrm{cm}^{3}$, whereas traffic locations exhibit $30.000-50.000 \# / \mathrm{cm}^{3}$. Since the total particle number is generally dominated by local emissions, it is particularly affected by primary particles generated by vehicle exhausts. Therefore, as found in previous studies [32], UFP total number concentrations measured at Via Montebello - close to traffic emissions - showed tendencies significantly different from the concentrations measured just 700 meters away in the park; representative of the urban background. Differences related mainly to two factors. The traffic site showed the UFP total number to have both much higher concentrations, and much more rapid fluctuations (Figures 5-8). Much faster and more intensive dilution processes could result in a more rapid reduction of UFP total number, as well as a trigger for other physical processes (such as nucleation) in connection to other parameters, such as solar radiation. Concentrations are comparable only at nighttime, from midnight to 4.00 a.m., when both the traffic flow and the concentration fluctuations at the Montebello station were very low.

Contrary to the urban background site, the total number concentrations at the traffic location showed a daytime trend shaped by two peaks (Figure 10). They can be likely related to traffic rush hours (7.00 a.m. and 18:00), and were also 


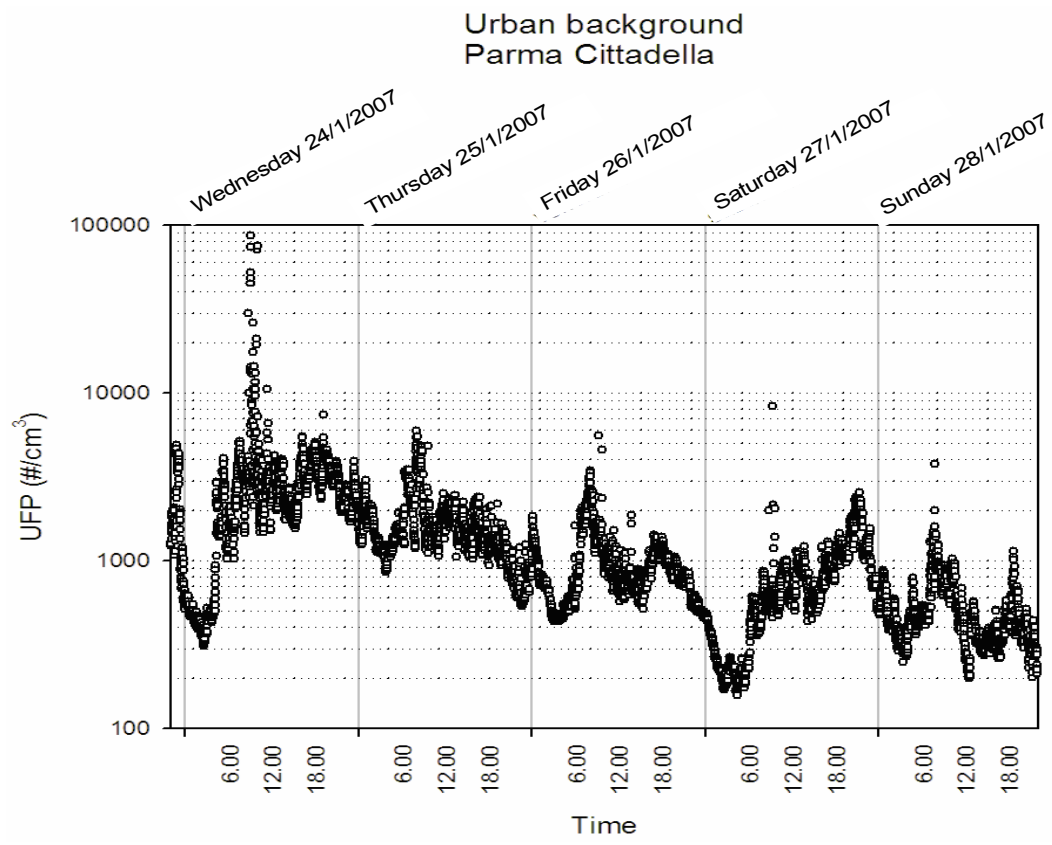

Figure 5: UFP number concentration during the winter campaign at an urban background station in Parma [23].

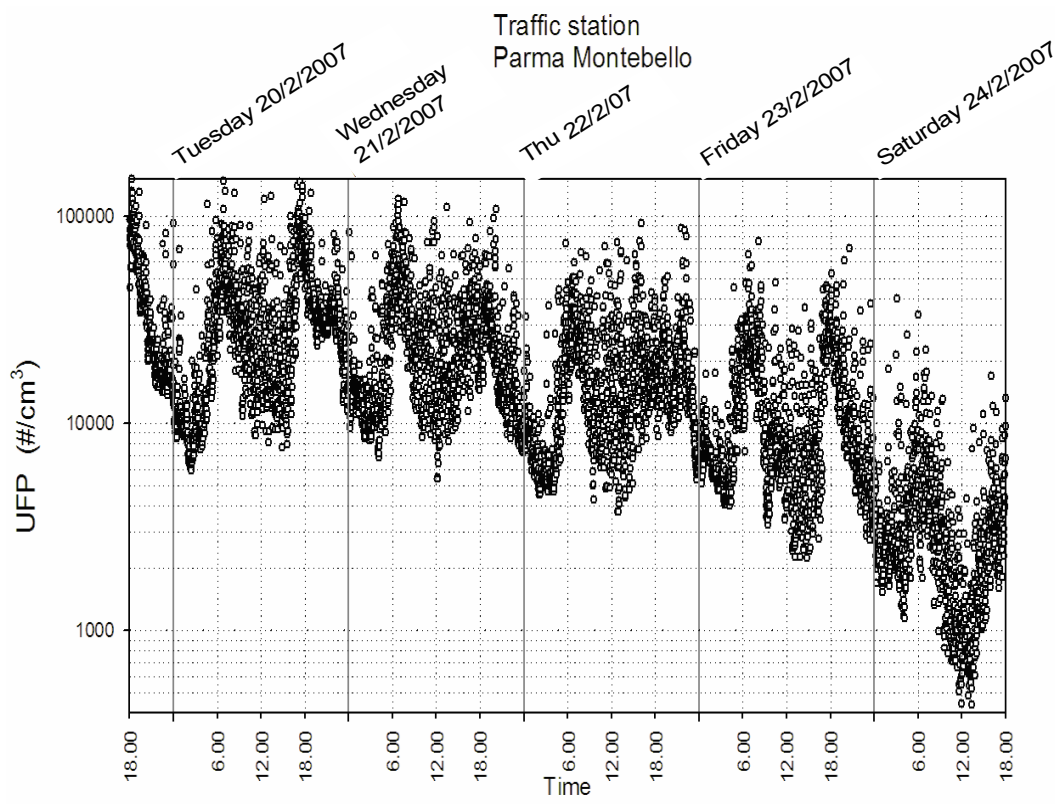

Figure 6: UFP number concentration during the winter campaign at a traffic station in Parma [23]. 


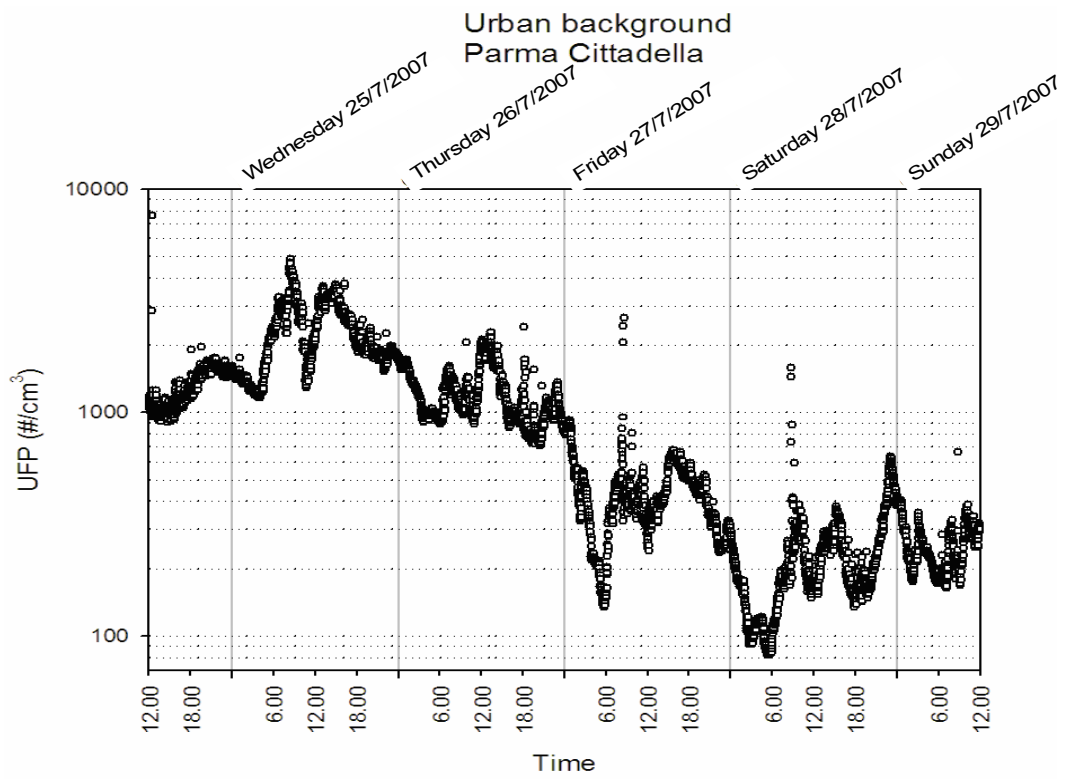

Figure 7: UFP number concentration during the summer campaign at the background station in Parma [23].

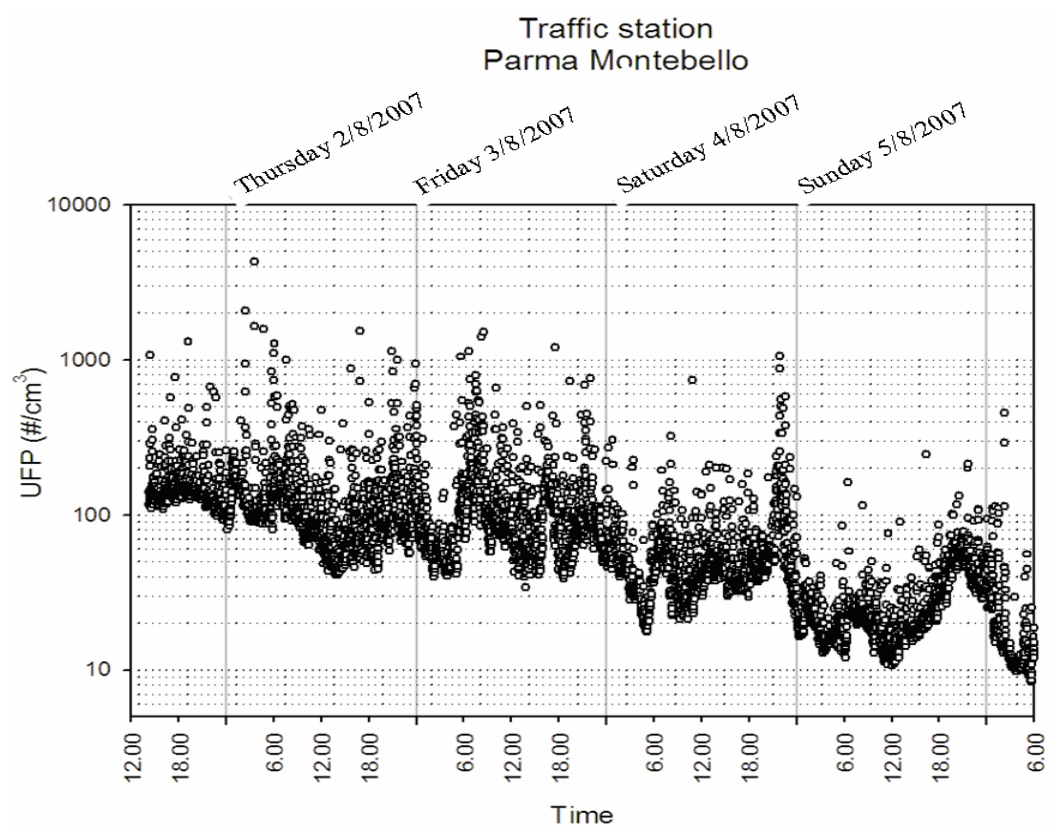

Figure 8: UFP number concentration during the summer campaign at a traffic station in Parma [23]. 
shown by other gaseous pollutants. This finding clearly indicates traffic emissions to be the prevailing source of the UFP total number [33].

\subsection{Coupling with meteorology and gaseous pollutants}

Variations due to meteorology can be more easily analysed at the urban background site, where traffic flows influence can, however, also be recognised. UFP total number concentration peaks (relative or absolute peaks) measured in the Cittadella often corresponded to (midday) solar radiation peaks (Figures 5 and 7). This suggests the secondary particle formation to be more significant at the background site [31]. The highest value of UFP total number concentration (not including spikes) at this site was measured on January 19 (Figure 9). This
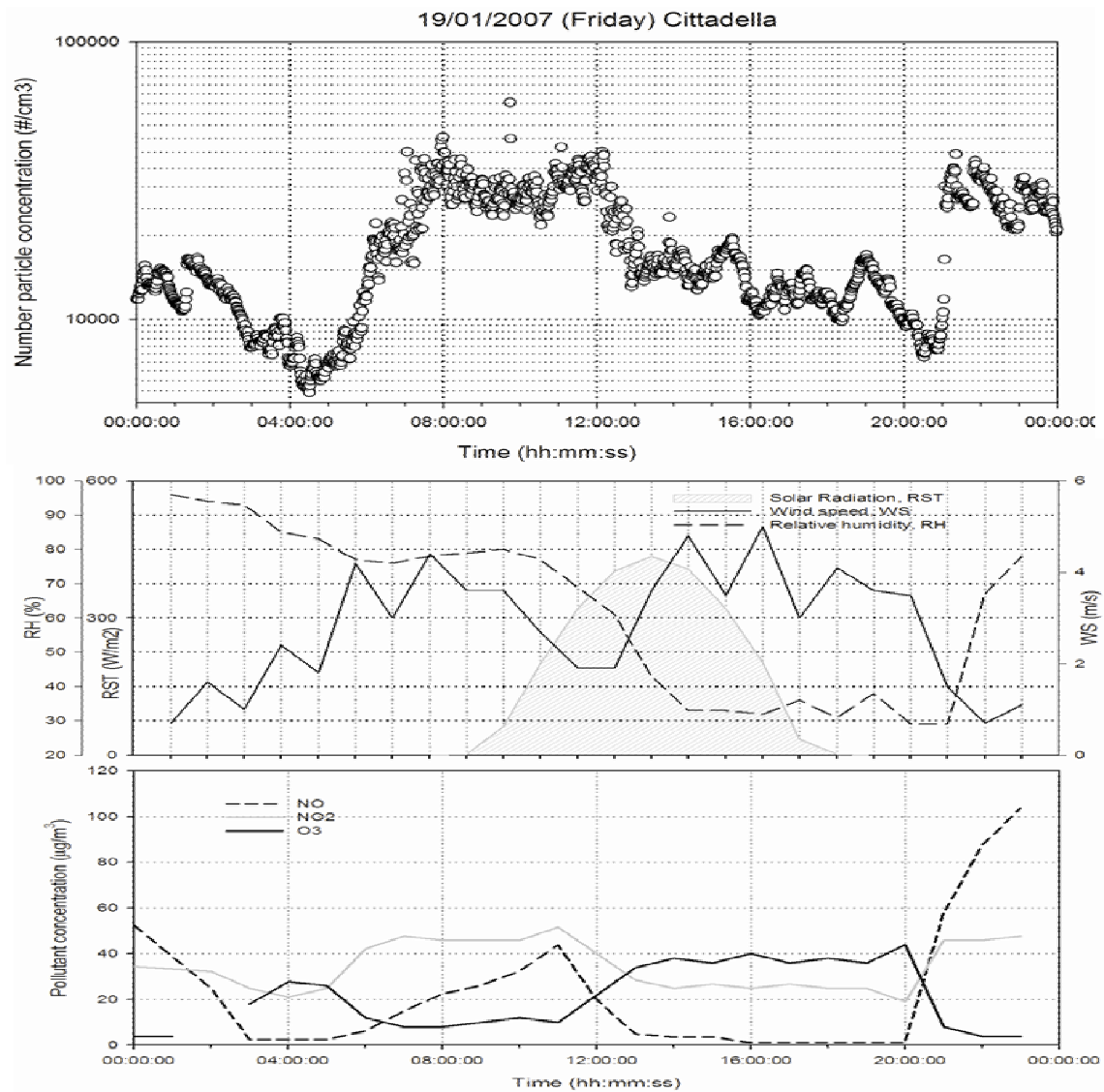

Figure 9: Total number concentration of UFPs measured at the background station (Parco della Cittadella) on Jan 19, 2007. Meteorological parameters and gaseous pollutant concentrations measured at the same site (ARPA Parma) are shown below. 


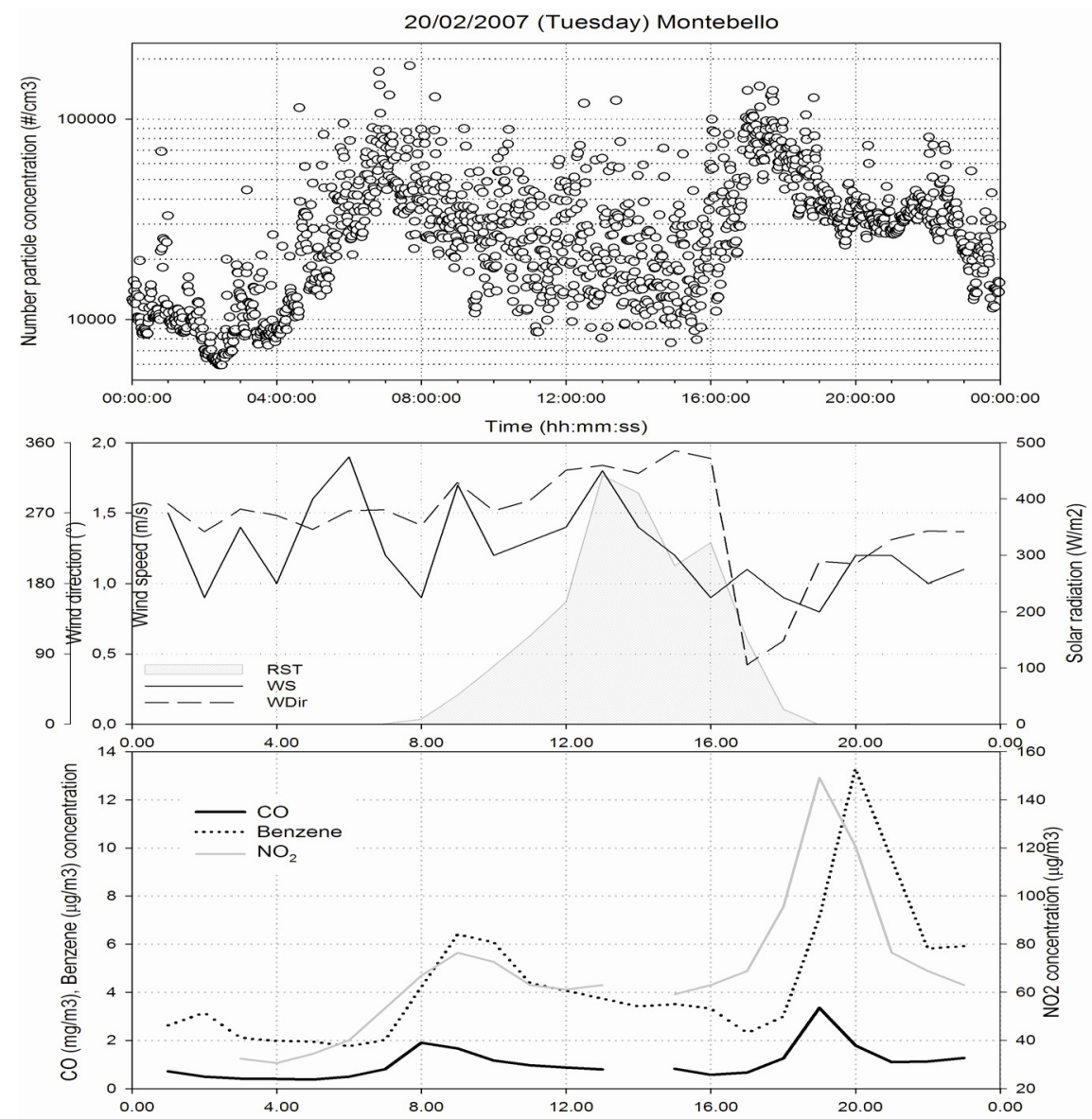

Figure 10: Total number concentration of UFPs measured at the traffic site (via Montebello) on Feb 20, 2007. Meteorological parameters and gaseous pollutant concentrations measured at the same site (ARPA Parma) are shown below.

was a weekday (Friday) with high solar radiation, temperature and wind speed, and low relative humidity.

Though less clear, these noontime peaks can also be seen at the traffic site (Figures 6, 8 and 10).

Beyond this effect, a correlation with wind speed was also found (Figure 9, Figure 10). It is not clear whether increased wind speeds can either induce significant transport phenomena of UFPs emitted/formed by nearby traffic sources [33], or enhance total number concentration by other phenomena (i.e., secondary new particle formation). This effect was less evident at the traffic site: local emitted particles effectively dominated measurements even when the site was upwind to the road nearby. It is not clear if the afternoon peak measured for 
both UFPs and gaseous pollutants on February, 20 in Montebello (Figure 10) should be related either to the wind direction change, or (more likely) to the lower wind speed (wind calm, $<1 \mathrm{~m} / \mathrm{s}$ ), the rush hours, and increased atmospheric stability. Interestingly enough, diurnal trends of both total UFPs number and primary gaseous pollutants (particularly $\mathrm{NO}$ and $\mathrm{CO}$ ) were found to be quite similar (Figures 9 and 10) [34, 35]. Different time resolutions of data collected (1min versus $1 \mathrm{~h}$ ) are likely the major reason for the differences in the fluctuations, and the related time shifts. These findings indicate the total UFP number as a valuable marker of fresh emissions at traffic stations, significantly correlated with combustion-generated pollutants.

Finally, the comparison between the frequency distributions of UFPs measured at the two sites (Figure 11) shows a double FD mode only at the urban background location. This could likely suggest the existence of an (extremely low) urban background level (the lowest mode, $1000 \# / \mathrm{cm}^{3}$, which can be recognised at both the sites). The second mode in the background location could be related to UFPs concentrations (extremely diluted) transported from nearby sources and already aged because of meteorology-induced transformations. The FD at the traffic site looks like an Ln-FD, suggesting mixing and dilution of local traffic source emissions to be the prevailing process over time $[29,36]$
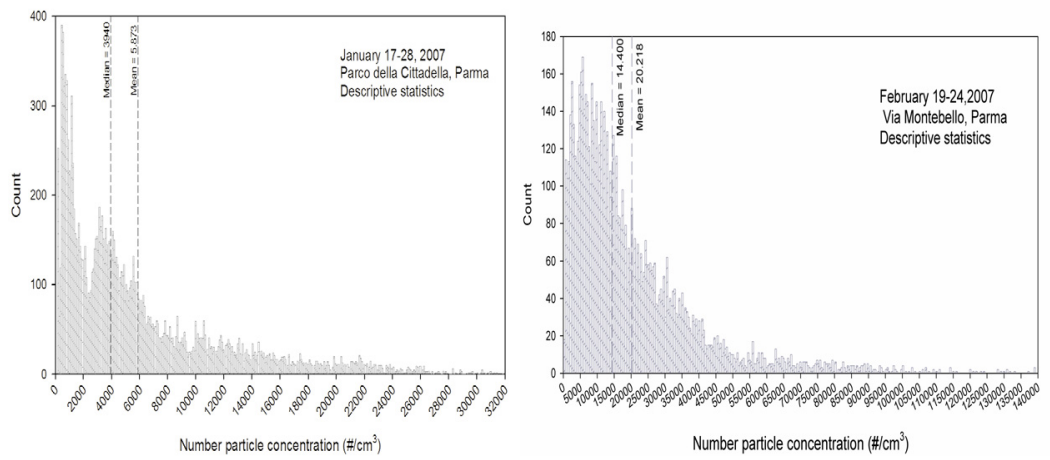

Figure 11: Frequency distribution of the total number concentration of UFPs measured at the background (Parco della Cittadella) and traffic (Via Montebello) stations.

\section{Conclusions}

The high-time resolution total number concentration of UFPs was analysed at traffic-oriented and urban background locations of a middle-size city in Italy. Total number concentration at the traffic site was found to be a clear indication of vehicle exhaust sources in ambient air. At an urban scale it was possible to identify three prevailing contributions for the total UFPs number concentration. Firstly, a very low urban background concentration (lower than $1000 \# / \mathrm{cm}^{3}$ ) was particularly visible in summer. Secondly, a significant contribution due to local 
traffic sources, up to $100.000 \# / \mathrm{cm}^{3}$ (traffic site in winter time). Finally, a significant contribution due to secondary transformation processes closely linked to meteorology, particularly solar radiation. Transport from sources nearby was also found to be significant, indicating significant UFP lifetime in the atmosphere. The conditions near mobile emission sources were found to differ from typical background conditions in that total particle number concentrations were much higher, and dilution processes were much faster and stronger. The stronger variability induced more rapid concentration fluctuations, probably due to faster and more intense dilution processes, which can reduce the number concentration more rapidly, as well as trigger physical processes other than dilution, such as nucleation, coagulation, and condensation.

\section{Acknowledgements}

Financial support mainly from the Italian Ministry of Environment, Land and Sea is gratefully acknowledged. As well, the authors would like to thank the ARPA-Parma (Regional Environment Protection Agency), and in particular Eriberto De Munari. Finally, our thanks are extended to our colleagues, F. De Santis, M. Montagnoli, and M. Giusto.

\section{References}

[1] Fenger, J., 1999. Urban air quality. Atmospheric Environment 33, 48774900

[2] Morawska, L. Vishvakarman, D. Mengersen, K. Thomas, S. 2002. Spatial variation of airborne pollutant concentrations in Brisbane, Australia and its potential impact on population exposure assessment. Atmospheric Environment 36, 3545-3555

[3] Briggs DJ. 2000. Exposure assessment. In: Elliott P, Wakefield JC, Best NG, Briggs DJ, editors. Spatial epidemiology: methods and applications. Oxford: Oxford University Press; p. 335-59

[4] Ito K, Xue N, Thurston G., 2004. Spatial variation of PM2.5 chemical species and source-apportioned mass concentrations in New York City. Atmos. Environ 38:5269-82.

[5] Kim E, Hopke PK, Pinto JP, Wilson WE, 2005. Spatial variability of fine particle mass, components, and source contributions during the Regional Air Pollution Study in St. Louis. Environ Sci Technol; 39:4172-9.

[6] Pinto JP, Lefohn AS, Shadwick DS., 2004. Spatial variability of PM2.5 in urban areas in the United States. J Air Waste Manage Assoc. 54, 440-9.

[7] Wilson JG, Kingham S, Pearce J, Sturman AP. A review of intraurban variations in particulate air pollution: implications for epidemiological research. Atmos Environ 2005;39:6444-62.

[8] Zhu, Y., Hinds, W.C., Kim, S., Shen, S., Sioutas, C., 2002. Study of ultrafine particles near a major highway with heavy-duty diesel traffic. Atmospheric Environment 36 (27), 4323-4335. 
[9] Lebret, E., Briggs, D., van Reeuwijk, H., Fischer, P., Smallbone, K., Harssema, H., Kriz, B., Gorynski, P., Elliott, P., 2000. Small area variations in ambient $\mathrm{NO} 2$ concentrations in four European areas. Atmospheric Environment 34, 177-185.

[10] WHO, 2006. Air Quality Guidelines. Global update 2005. WHO Regional Office for Europe, Copenhagen, Denmark (http://www.euro.who.int/ Document/E90038.pdf)

[11] Pekkanen, J. and Kulmala, M., 2004. Exposure assessment of ultrafine particles in epidemiologic time-series studies, Scandinavian Journal Work Environment and Health 30 (Suppl. 2), pp. 9-18

[12] Monn, C., 2001. Exposure assessment of air pollutants: a review on spatial heterogeneity and indoor/outdoor/personal exposure to suspended particulate matter, nitrogen dioxide and ozone. Atmospheric Environment 35, pp. 1-32.

[13] Weijers, E. P., Khlystov, A. Y., Kos, G. P. A., Erisman, J. W., 2004. Variability of particulate matter concentrations along roads and motorways determined by a moving measurement unit. Atmospheric Environment, 38 (19), 2993-3002.

[14] Charron, A., Harrison, R. M., 2003..Primary particle formation from vehicle emissions during exhaust dilution in the roadside atmosphere. Atmospheric Environment 37, 4109-4119

[15] Alam A., Shi Ping, J. and Harrison R. (2003), Observations of new particle formation in urban air. J. Geophys. Res. 108: D3, doi: 1029/2001/JD001417.

[16] Kittelson, D.B., Watts, W.F., Johnson, J.P., 2004. Nanoparticle emissions on Minnesota highways. Atmospheric Environment 38 (1), 9-19.

[17] Morawska, L., He, C., Hitchins, J., Mengersen, K., \& Gilbert, D. , 2003. Characteristics of particle number and mass concentrations in residential houses in Brisbane, Australia. Atmospheric Environment, 37, 4195-4203.

[18] Abdul-Khalek, I. S.; Kittelson, D. B.; Brear, F. , 1999. Influence of dilution conditions on diesel exhaust particle size distribution measurements. SAE Technol. Pap. Ser., no. 1999-01-1142

[19] Scheer, V., Kirchner, U., Casati , R., Vogt, R., Wehner, B., Philippin ,S., Wiedensohler, A., Hock, N., Schneider, J., Weimer , S., Borrmann, S., 2005. Composition of Semi-volatile Particles from Diesel Exhaust. SAE Paper 2005-01-0197

[20] Giechaskiel, B.; Ntziachristos, L.; Samaras, Z.; Scheer, V.; Casati, R.; Vogt, R.; Van Grieken, 2005. Formation potential of vehicle exhaust nucleation mode particles on-road and in the laboratory. Atmospheric Environment 39, 3191-3198

[21] Shi, J.P., Evans, D.E., Khan, A.A., Harrison, R.M., 2001. Sources and concentration of nanoparticles (10nm diameter) in the urban atmosphere. Atmospheric Environment 35, 1193-1202

[22] Ketzel, M, Berkowicz, R., 2004. Modelling the fate of ultrafine particles from exhaust pipe to rural background: an analysis of time scales for 
dilution, coagulation and deposition. Atmospheric Environment 38, 26392652

[23] Costabile, F., Allegrini, I,.., 2007b. Measurement and analysis in space and time of ultrafine particle number concentration in ambient air. The case of Parma. Proceeding of the International Conference UFIPOLNET, Dresden (Germany), 23-24 October 2007, pp.56-57

[24] Petäjä, T.; Mordas, G.; Manninen, H.; Aalto, P. P.; Hämeri, K.; Kulmala, M., 2006. Detection Efficiency of a Water-Based TSI Condensation Particle Counter 3785 Aerosol Science \& Technology, 40(12):1090-1097

[25] Hering, S. V., Stolzenburg, M. R., Quant, F. R., Oberreit, D. R., and Keady, P. B., 2005. A Laminar-Flow, Water-Based Condensation Particle Counter (WCPC). Aerosol Sci. Technol. 39:659-672

[26] Hering, S. V., and Stolzenburg, M. R. (2005). A Method for Particle Size Amplification by Water Condensation in a Laminar, Thermally Diffusive Flow. Aerosol Sci. Technol. 39:428-436

[27] Biswas, S., Fine, P. M., Geller, M. D., Hering, S. V., and Sioutas, C., 2005. Performance Evaluation of a Recently Developed Water-Based Condensation Particle Counter. Aerosol Sci. Technol. 39, 419-427

[28] TSI, operating manual, 2006.

[29] Costabile, F., Bertoni, G., Desantis, F., Wang, F., Hong, W., Liu, F., Allegrini, I., 2006. A preliminary assessment of major air pollutants in the city of Suzhou, China. Atmospheric Environment 40 (33), 6380-6395.

[30] Costabile, F., Desantis, F., Wang, F., Hong, W., Liu, F. and Allegrini, I., 2006. Representativeness of Urban Highest Polluted Zones for Siting Traffic-Oriented Air Monitoring Stations in a Chinese City. JSME International journal-B 49 (1), 35-41

[31] Harrison, R.M., Jones, M., Collins, G., 1999. Measurements of the physical properties of particles in the urban atmosphere. Atmospheric Environment 33, 309- 321

[32] Zhang, K. M., Wexler, A.S., Zhu, Y.F., Hinds, W. C., Sioutas, C., 2004a. Evolution of particle number distribution near roadways. Part II: the 'Roadto-Ambient' process. Atmospheric Environment 38, 6655-6665

[33] Shi, J.P., Khan, A.A., Harrison, R.M., 1999. Measurements of ultrafine particle concentration and size distribution in the urban atmosphere. The Science of Total Environment. 235, 51-64..

[34] Kittelson, D.B., Watts, W.F., Johnson, J.P., Rowntree, C., Payne, M., Goodier, S., Warrens, C., Preston, H., Zink, U., Ortiz, M., Goersmann, C., Twigg, M.V., Walker, A.P., Caldow, R., 2006. On-road evaluation of two Diesel exhaust aftertreatment devices. Aerosol Science 37, 1140 - 1151

[35] Kittelson, D.B., Watts, W.F., Johnson, J.P., Schauer, J.J., Lawson, D.R., 2006b. On road and laboratory evaluation of combustion aerosol-Part 2: summary of spark-ignition engine results. Aerosol science 37, 931-949.

[36] Ott, W.R.A., 1990. Physical explanation of the lognormality of pollutant concentrations. Journal of Air and Waste Management Association 40, 1378-1383. 